\title{
DECISION MAKING FOR SURGERY IN ADULT SCOLIOSIS REVIEW OF THE CURRENT LITERATURE
}

(1) Kadir ABUL

\author{
University of Health Sciences, Gaziosmanpaşa Training and Research Hospital, Clinic of Orthopedics and Traumatology, İstanbul, Turkey
}

\begin{abstract}
Adult spinal deformity is a challenging condition in spine surgery. Adult scoliosis (AS) is an important health issue with potential to cause severe surgical adverse ramifications in aging population. Deciding who is going under the knife is still a debatable issue with no clear algorithm. This review of the recent literature is representative of the results of modern intervention methods and it references to competent authorities aiming to help clinicians to supply a guideline for surgical decision making in AS. A search in the National Library of Medicine (PubMed) database using keywords AS was performed. Our search yielded 4247 articles published between January 2005 and March 2019. When added the "surgical decision", it accounted for 105 articles. For the literature review, of papers, especially focusing on surgical decision-making, 27 were selected as guiding articles.

Non-surgical interventions for symptomatic AS cases lack a high level of evidence. Successful results were reported for local decompression, limited short segment fusion, and deformity correction with long segment fusion surgeries for selected cases. Leading factors for surgery seems to be a symptomatic case with a functional problem (primarily painful radiculopathy), self-image problems, a higher curve, and recently with an extra emphasis on sagittal malalignment. Patient's expectations, pain intensity, functional status, perception of self-image and medical risk stratification, surgeon's experience, and contentment will shape the strategy needed for decision-making for surgery and whether to address either a focal pathology or comprehensive deformity correction. Every case has to be managed according to its own characteristics.

Keywords: Adult scoliosis, degenerative, idiopathic, decision-making process, surgical indication, spine surgery
\end{abstract}

\section{INTRODUCTION}

Adult scoliosis (AS) is a term to define a lateral curvature of the spine more than 10 degrees of Cobb curve with accompanying vertebral axial rotation in a skeletally mature spine $e^{(47,13)}$. The incidence of AS is approximately $1.4-32 \%$, and as high as $68 \%$ in patients over 60 years of age in a healthy adult population ${ }^{(74)}$ and it is rising in conjunction with the aging population. Young patients with scoliosis almost always have a self-image complaint when they have been first seen in the clinic. However, patients with AS, in addition to deformity and cosmesis, mostly have a complaint like pain, neurological deficits, and psychosocial concerns namely "disability". Two main types of AS are idiopathic and degenerative subtypes. Idiopathic form is a continuation of an infantile or adolescent onset diagnosis whereas degenerative or so-called "de novo scoliosis" is believed to develop through asymmetric disk space collapse and facet degeneration with subsequent lateral and/or rotatory listhesis ${ }^{(7)}$. Differentiation of adult degenerative scoliosis from idiopathic counterpart can be somewhat confusing because of the complexity of the disease process and difficulties in the description and classification of the deformity. Sometimes it is very challenging to discriminate degenerative scoliosis just by inspecting the X-ray images. Even so, there are some clues for radiological differentiation. For idiopathic AS, deterministic factors are younger age, larger Cobb angled curves $\left(>40^{\circ}\right)$, an obvious compensatory curve, and a rotatory deformity along the whole curve. On the other hand, degenerative cases have an older age ( $>50)$, lesser curve size $\left(<40^{\circ}\right.$ Cobb angle), a rotatory deformity at the apex, and a higher incidence of spinal stenosis, lateral vertebral subluxation of vertebral body, and sagittal

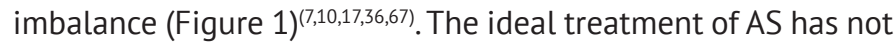
yet been identified; both surgeons and clinicians face multiple challenges, including non-surgical and surgical treatment. For surgical treatment; choosing the included segments, preserving lower lumbar vertebrae and pelvis, setting ideal sagittal and coronal alignment, the ideal age, timing for surgery, and maybe still some cosmetic issues as in AIS should be concerned. In addition, deciding whether to go for surgery or to perform which surgical intervention (local decompression, short segment fusion or longer fusions) is limited to "expert opinion or surgeon's personal bias in the facility which they were educated". However, patients with AS constitute a heterogeneous population with a clinical complaint and additional degenerative changes, thus, it is difficult to compare the outcomes of different management strategies in meaningful 
numbers of patients. In addition, there is still a lack of outcome assessment tools for this complex group of patients. The factors affecting the surgical decision in the literature are mainly from "what we did and succeeded or failed" inferences. These mainly focus on patient-reported outcome measurements (PROMs) and complication rates. If one surgery has a significant improvement in health-related quality of life (HRQoL) and with a low complication rate on a similar group of AS patients, then it is logical to choose more patients in the same condition, who are waiting for a decision to be made. Through the past two decades, understanding the importance of the restoration of normal sagittal alignment is one of the fundamental goals in deformity correction surgery, and rod pre-contouring is a standard procedure in almost all modern correction techniques for sagittal alignment control. However, defining ideal sagittal shape and alignment for the surgically corrected spine is still a debatable topic today(26,27,49,71). AS was found to have a devastating effect on HRQoL in several studies ${ }^{(5,61)}$, like the Short Form-36 Physical Component Score values for this cohort were similar to the values reported by patients with chronic heart disease, and the disease impact of large sagittal malalignment (sagittal vertical axis $>10 \mathrm{~cm}$ ) was greater than that reported by patients with limited vision and patients with limited use of arms and legs. A reputable classification system for AS should be that it distinguishes between clinically significant groups of cases with the disease, it is easy to apply in clinical settings, it is reproducible over time and among observers, it guides the surgical treatment, and it predicts outcomes. Ad hoc, first, King and Lenke classifications took place for adolescent scoliosis in 1983 and 2001, respectively, and then the need for more comprehensive definitions arose
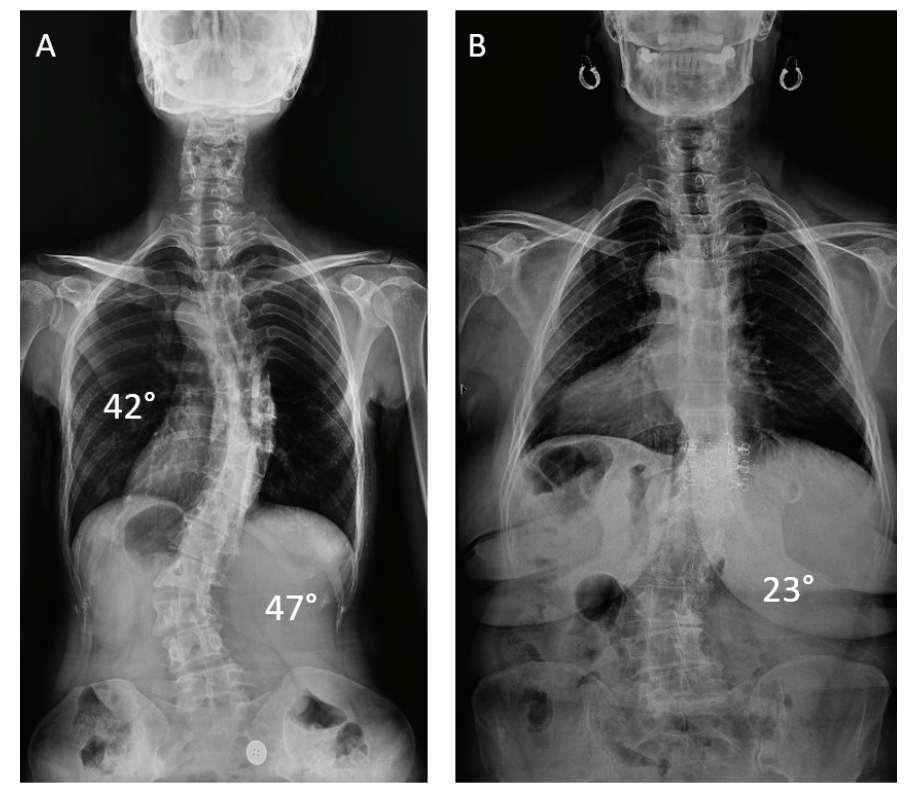

Figure 1. Case examples for 37 years old patient with idiopathic (A) and a 67 years old patient with degenerative adult scoliosis. Note the lesser curve size and absence of compensatory curve in (B) for AS. The Simmons classification system ${ }^{(55)}$, Aebi $^{(1)}$, Scoliosis Research Society ${ }^{(4)}$ and the SRS-Schwab Adult Spinal Deformity Classification $^{(6)}$ have emerged for these needs. One put effort to cover others' inadequacy, mainly focusing not only the coronal deformity but also the sagittal alignment and the disabled state of the patient. The simple pathogenesis-based approach of $\mathrm{Aebi}^{(1)}$, the strong clinical relevance of the Schwab approach, and the richly descriptive SRS systems all gained popularity. Moreover, the ideal classification system for AS continues be re-evaluated researchers. Many groups continue to devise classification systems as both surgical techniques and the understanding of scoliosis are refined. During the past decade, advancements in surgical techniques, instrumentation, supported with the multidisciplinary advance in anesthesia, radiology, and understanding the importance of sagittal global alignment and its proportions have changed the management of adult spinal deformity surgery and led to improved longterm outcomes. Therefore, this study focuses on the current literature for reliable and valid information.

\section{MATERIALS AND METHODS}

A search in the National Library of Medicine (PubMed) database using the keywords AS' has yielded 4247 articles published between January 2005 and March 2019. When added the "decision", it accounted for 105 articles. All information on outcome measures was extracted. Referenced clinical studies were retained in full text analyzed. We assessed the quality of each study based on following criteria: minimal number of patients, construct validity, internal consistency, criterion validity, reproducibility, responsiveness, up-to-dateness, and interpretability. As a result, 27 papers, especially focusing on surgical decision-making, were selected for the review (Figure 2) (Table 1).

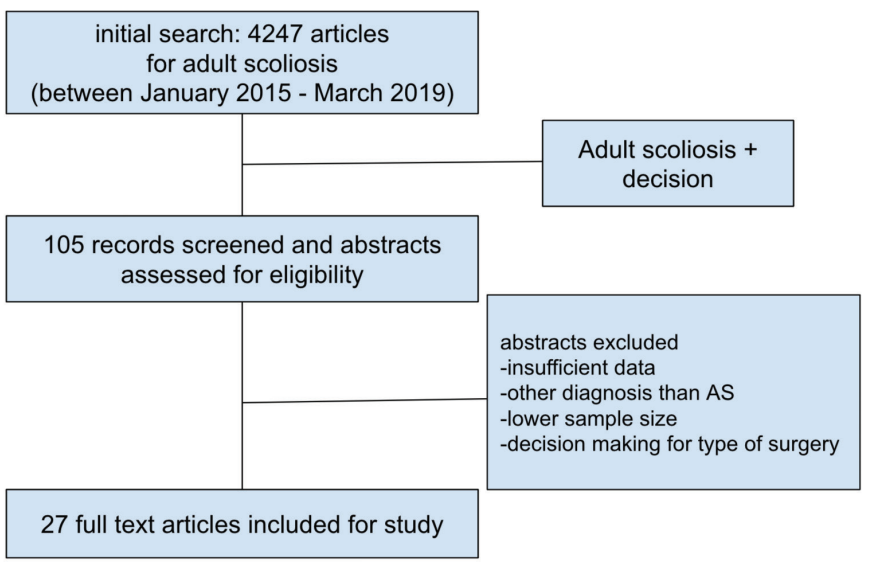

Figure 2. Flowchart of the study selection process

\section{DISCUSSION}

The PROMs, the intensity of symptoms, patient demographics, accompanying co-morbidities, coronal deformity and imbalance, 
Table 1. Papers and remarks related to decision making for surgery in adult scoliosis

\begin{tabular}{lllll}
\hline $\begin{array}{l}\text { Publish } \\
\text { year }\end{array}$ & Author & $\begin{array}{l}\text { Study } \\
\text { design }\end{array}$ & $\begin{array}{l}\text { Cobb } \\
\text { curve }\end{array}$ & Remarks \\
\hline 2006 & Glassman et al. ${ }^{(21)}$ & RP & $>30^{\circ}$ & Sagittal plane deformity, worse PROMs more in surgical groups \\
\hline 2007 & Glassman et al. ${ }^{(24)}$ & RP & $>30^{\circ}$ & $\begin{array}{l}\text { Nonsurgical patients had greater preoperative medical risk factors. Surgical patients } \\
\text { had more frequent leg pain, a higher mean level of daily back pain, and more frequent } \\
\text { moderate-to-severe back pain }\end{array}$ \\
\hline 2008 & Smith et al. ${ }^{(57)}$ & RP & $>20^{\circ}$ & $\begin{array}{l}\text { Development of neurological symptoms and/or deficits is strongly associated with the } \\
\text { decision to pursue operative treatment }\end{array}$ \\
\hline
\end{tabular}

\begin{tabular}{|c|c|c|c|c|}
\hline 2009 & Pekmezci et al.(39) & $\mathrm{R}$ & $>30^{\circ}$ & $\begin{array}{l}\text { BMI, comorbidity scores, back pain, and leg pain incidence, and severity were similar } \\
\text { among operative or nonoperative groups. Functional limitations are more important } \\
\text { than pain for adult deformity patients when deciding for operative or nonoperative } \\
\text { treatment }\end{array}$ \\
\hline 2009 & Smith et al. ${ }^{(58)}$ & $\mathrm{RP}$ & $>10^{\circ}$ & $\begin{array}{l}\text { Compared to nonoperative treatment, surgery can offer significant improvement of } \\
\text { back pain for adults with scoliosis }\end{array}$ \\
\hline 2009 & Smith et al. ${ }^{(59)}$ & $\mathrm{RP}$ & $>10^{\circ}$ & $\begin{array}{l}\text { Surgical treatment has the potential to provide significant improvement of leg pain } \\
\text { in adults with scoliosis }\end{array}$ \\
\hline 2009 & Wood et al. ${ }^{(67)}$ & $\mathrm{R}$ & $>30^{\circ}$ & $\begin{array}{l}\text { Patients treated operatively reported significantly less pain and better health-related } \\
\text { quality of life, self-image, mental health, and global restoration. } \\
\text { Preoperative radiographic parameters were not determined to be a significant factor } \\
\text { for predicting whether an operative or nonoperative treatment course was chosen }\end{array}$ \\
\hline 2009 & Bridwell et al. ${ }^{(8)}$ & $\mathrm{P}$ & $>30^{\circ}$ & $\begin{array}{l}\text { Common nonoperative treatments do not change the HRQoL in patients with ASLS } \\
\text { at 2-year follow-up. However, operative treatment does significantly improve HRQDL }\end{array}$ \\
\hline 2010 & Fu et al. (20) & PR & $>20^{\circ}$ & $\begin{array}{l}\text { Operative intervention group reported worse health, greater disability and had a } \\
\text { higher level of comorbidity. } \\
\text { Relative contraindications to surgery; age greater than } 75 \text { years and a Charlson } \\
\text { Comorbidity Index score greater than } 5 \text { are used as discouraging criteria }\end{array}$ \\
\hline 2011 & Smith et al. ${ }^{(61)}$ & PR & $>30^{\circ}$ & $\begin{array}{l}\text { Elderly, despite facing the greatest risk of complications, may stand } \\
\text { to gain a disproportionately greater improvement in disability and } \\
\text { pain with surgery }\end{array}$ \\
\hline
\end{tabular}

$2011 \quad$ Kotwal et al.(30) Review - $\quad \begin{aligned} & \text { The presence of lateral listhesis, spondylolisthesis, and sagittal or coronal } \\ & \text { decompensation, despite a low Cobb angle, is believed to be more important in } \\ & \text { decision-making }\end{aligned}$

$2012 \quad$ Lonergan et al. ${ }^{(33)} \quad \mathrm{R} \quad-\quad \begin{aligned} & \text { Age alone should not be the deciding factor or a contraindication for patients in their } \\ & 8^{\text {th }} \text { decade of life who are incapacitated by their painful spinal deformity }\end{aligned}$

$2014 \quad$ Cho et al.(10) Review - Short fusion is indicated in cases with less Cobb angle, minimal rotational deformity, and no coronal and sagittal imbalance.

Long fusion is indicated in cases of severe Cobb angle and coronal and sagittal imbalance

\begin{tabular}{rllll}
\hline 2015 & Sciubba et al. ${ }^{(50)}$ & PR & $>20^{\circ}$ & Surgery provides significant improvements in pain and disability in patients aged $>75$ \\
\hline 2015 & Scheer et al. ${ }^{(4)}$ & PR & $>20^{\circ}$ & $\begin{array}{l}\text { Surgical management resulted in significantly greater improvement in both back and } \\
\text { leg pain severity than nonsurgical management. } \\
\end{array}$ \\
& & $\begin{array}{l}\text { Moreover, patients whose ASD was managed nonsurgically were more likely to } \\
\text { experience no improvement or worsening of their pain }\end{array}$
\end{tabular}

2015 Smith et al. ${ }^{(58)} \quad \mathrm{P} \quad>20^{\circ} \quad$ Operative treatment for ASD can provide significant improvement of HRQoL at a minimum 2-year follow-up.

In contrast, nonoperative treatment on average maintains presenting levels of pain and disability 


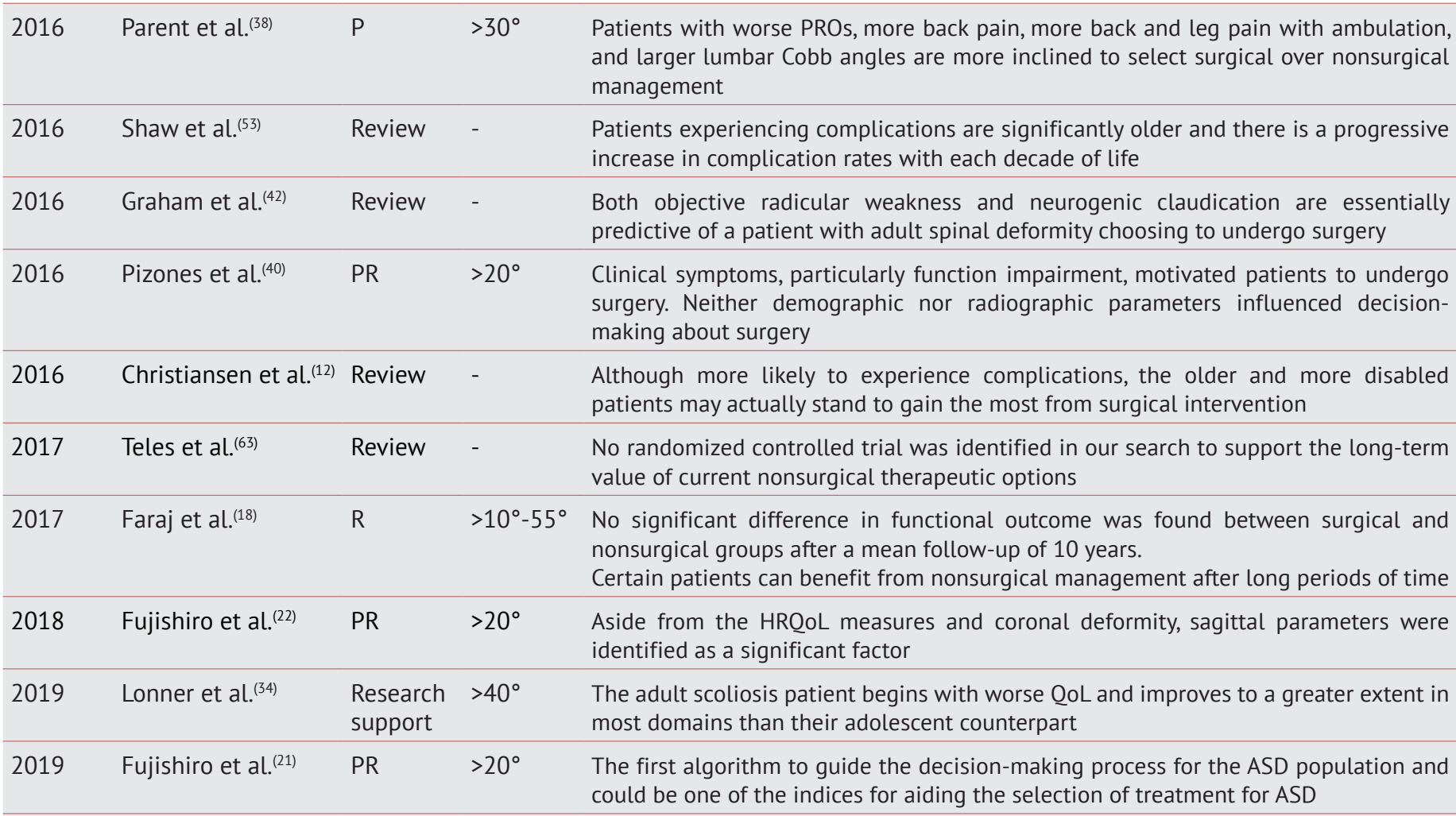

RP: Retrospective review of prospectively collected data; R: Retrospective study, P: Prospective study, AS: Adult scoliosis, PROM: Patient-reported outcome measure, HRQoL: Health-related quality of life, BMI: Body mass index, ASD: Adult spinal deformity, ASLS: Adult symptomatic lumbar scoliosis

and sagittal malalignment all have a part in decision-making to pursue surgery for AS patients. Most studies have examined the factors influencing decision-making in AS by questioning the distinguishing determinant factors among surgical and nonsurgical cases.

\section{Conservative Treatment}

Initial management of symptomatic AS, without progressive neurologic deficit, basically comprises non-surgical treatments in order to avoid the inherent morbidity of extensive surgeries. However, nonsurgical modalities play a little role in ASD and there is a lack of evidence in the literature and most of the existing evidence is derived from observational studies with a high risk of bias ${ }^{(16,41,58,63,)}$. On the contrary, there is literature evidence of supporting conservative interventions for selected cases. Non-operative methods should be tried first and all means be consumed before the talk of surgery ${ }^{(32,50,56)}$. Conservative treatment includes aerobic exercise, aquatics/pool therapy, strength training, stretching exercises, postural training, body mechanics physical agents methods, analgesics, nonsteroidal anti-inflammatory drugs, narcotics, pain management, epidural blocks, facet or nerve root injections, bracing, bed rest, weight loss programs or "no treatment". On the other hand, there is the option of "surgical treatment" with up to $80 \%(9.52 \%$ $81.52 \%$ ) complication rates and more than $50 \%$ re-operation rate, reported in several papers ${ }^{(8,9,63,68)}$. Teles et al. ${ }^{(62)}$ reported postoperative radiological (7 main categories) and instrumentrelated (7 main categories) complications and Christiansen et al. ${ }^{(12)}$ modified their work and stated 46 major and 41 minor complications under 10 main categories (infection, implantrelated, neurological, cardiopulmonary, gastrointestinal, radiographic, renal, wound problems, operative, and vascular). Surgery may be considered if patients have inadequate improvement with nonoperative measures. Thus, researchers sought for the answer to the question: "why all these patients still choose the operative treatment, despite this much complication rate?".

\section{Why Surgery?}

Answers to this question were given by several studies in the scope of risks and benefits. Smith et al.(58) compared propensitymatched 286 operative and 403 nonoperative patients and reported that $71.5 \%$ of operative patients had at least 1 complication, and reported still significant improvements in HQRoL measurements. Bridwell et al. ${ }^{(8)}$ revealed 31 complications among 85 operated patients and still reported improvements in all HRQoL parameters. Zimmerman et al. ${ }^{(73)}$ also stated that in spite of high complication rates (49\%), patients benefited from surgery. Trommell et al. ${ }^{(64)}$ grouped patients in three categories as decompression only, decompression with limited fusion and long fusion and they concluded similar inference with prementioned studies in improvements in PROMs contrast to complications. First three studies also emphasized little or no change in PROMs in non-operative groups in the follow-up. Moreover, Smith et al. ${ }^{(57,60)}$ reported in two different studies that despite having started with significantly greater leg, back pain 
turkishspine

and disability, surgically treated patients at 2-year follow-up had significantly less pain and disability than nonoperatively treated patients who gained nearly no improvement. Surgery has been shown to be superior to non-operative treatment in AS patients with severe disability ${ }^{(8,49,50)}$.

\section{Back Pain}

Back pain is the most common symptom of AS and widely a subjective quality of life measure. It usually presents on the convex side of the curvature. It has been found that the prevalence of back pain in scoliotic adults is no higher than that in the normal population ${ }^{(25)}$. Back or leg pain that is refractory to conservative measures is an indication for surgery. Ha et al.(25) found that low back pain was no more severe in patients manifesting with lumbar scoliosis than in nonscoliotic cases; however, a specific pain profile, notably a high frequency of cruralgia and inguinal pain, existed for scoliotic patients.

\section{Radicular Pain (Neurological Symptoms and Deficit)}

Spinal canal or concave side neuroforaminal stenosis related to either degenerative changes or the scoliotic curve itself can enhance severe enough to result in neurological deficits. Both objective radicular weakness and neurogenic claudication are essentially predictive of a patient with adult spinal deformity, choosing to undergo surgical intervention ${ }^{(57)}$.

Plenty of reports have showed that the presence of leg pain is an independent predictor of a patient's preference for surgical over nonsurgical care ${ }^{(23,39,57,73)}$. Smith et al. ${ }^{(57)}$ described a bestfit model for a surgery candidate as having 3 of these: severe radiculopathy, radicular weakness, and greater sagittal imbalance. They also excluded the severe back pain from their model.

\section{Age}

There is a clear connection between increasing age and higher rates of major short-term complications, a factor that ought to be taken into account during decision-making for treatment and patient counseling ${ }^{(14,33,53)}$. Older age was once reported to be a relative contraindication ${ }^{(20)}$. However, in spite of higher complication rates, more recent studies are in favor of surgery because of its positive impact on PROMs ${ }^{(50,64,74,)}$. Bess et al. ${ }^{(5)}$ in their study, stratified their patients into 3 groups $(\mathrm{G} 1<50$ years, $\mathrm{G} 2=50-65$ years, $\mathrm{G} 3>65$ years) and demonstrated larger curves in $\mathrm{G} 1$ and $\mathrm{G} 2$ versus $\mathrm{G} 3$, progressively worsening sagittal imbalance in older age groups, and worse HRQoL scores in G3 versus $\mathrm{G} 1$ and $\mathrm{G} 2$.

A very sophisticated study is from Lonner et al. ${ }^{(34)}$ They matched 28 AS patients with 56 (1:2) AIS patient, estimating their natural history of curve progression as a future equivalence of AIS deformities. They found the adult counterparts having greater levels fused, longer operative time, and higher complication rates than the AIS counterpart. Therefore, they emphasized the negative effects of waiting for surgery.

\section{Comorbidities}

$\mathrm{Fu}$ et al.(20) suggested criteria for relative contraindications to surgery as; age greater than 75 years and a Charlson
Comorbidity Index score greater than five. In contrast, Seboaly et al. ${ }^{(50)}$ reported that in elderly patients greater than 75 years of age, reconstructive surgery can provide significant improvements in pain and disability over a two-year period. The presence of comorbidities, like the age, was once perceived as a restrictive factor for surgical intervention. However, this does not necessarily result in poor outcomes in recent literature, and favorable outcomes are not without complications ${ }^{(12,74)}$. Somehow, higher risk subjects potentially have more to gain, even if they encounter complications ${ }^{(12,50,61)}$.

\section{Extension of Surgery}

While some authors favor the local decompression in selected cases $^{(64,73)}$, others advise it should be avoided to protect further curve progression ${ }^{(10)}$. One important issue is that if a long segment fusion surgery is decided for an AS case, the sagittal profile must be corrected properly to avoid postoperative complications ${ }^{(4,64,70)}$. Based on this, in case of a patient with a severely disproportioned (SD) sagittal spine profile, if one cannot properly restore the sagittal alignment, it is better to do a focal solution or even no surgery.

\section{Patient-reported Outcome Measurements}

Several researchers have studied factors influencing decisionmaking in AS by examining the distinguishing factors between surgical and nonsurgical cases. These factors mainly include the PROMs, the intensity of symptoms, coronal and sagittal imbalance, comorbid state of the patient, and demographics for selecting surgical management and provide information on the decision-making process for the adult spinal deformity (ASD) population. Worse HRQoL scores [Oswestry Disability Index (ODI) $>20$, SRS <4] in surgically treated groups were reported to be prevalent than the nonsurgical comparisons $(8,20,22,38,39,50,57,74)$ and after the surgical recovery period passed, these measures were also reported to be improved significantly in surgery cohorts, while the nonsurgical group remained with no significant change ${ }^{(8,50,74)}$. Glassman et al. ${ }^{(23)}$, in a database of 585 nonsurgical ASD patients, divided the group into highsymptom (335) and low-symptom (250) subgroups, based on age-adjusted ODI scores and found that the 2 groups differed significantly on all standardized patient-reported health status measures $(p<0.0001)$. Patients in the low-symptom group (49\% vs. $38 \%$ ) had a primary diagnosis of adult idiopathic scoliosis $(<0.01)$. In the same paper, they also compared 335 high-symptom patients with 476 surgical ASD cases and found a higher incidence of sagittal plane deformity in favor of the surgical group.

\section{Lateral Listhesis and Rotatory Subluxation}

Lumbar lateral listhesis is common in AS and it is reported in $13 \%-34 \%$ of cases and it is stated to be an important finding leading to radiculopathy ranging between 43 and $65 \%^{(19,29)}$. The incidence of back pain in patients with AS and rotatory subluxation has been reported as high as $80 \%{ }^{(65)}$. Rotatory subluxation seems to be the initial element of progression 
for degenerative scoliosis, while it is the consequence of progression for idiopathic scoliosis(36).

Glassman et al.(24) and Wood et al.(67) found that the greater apical vertebral translation led to an increased likelihood of surgical treatment among radiological parameters. In contrast, Pizones et al.(40) found no differences between surgical and nonsurgical groups in terms of radiographic preoperative data, including Apical translation and lumbar rotatory subluxation. Ferrero et al. ${ }^{(19)}$ found a correlation between PROMs and rotatory subluxation as the number of level increase significantly correlated with ODI scores.

\section{The Coronal Curve Imbalance}

Sagittal analysis has been broadly outlined in the literature during the past decade, whereas coronal deformity (as it should be a straight line), took little attention. Not like AIS patients, flexibility is limited in AS cases. Coronal alignment seems to have limited influence on the intensity of pain and functional disability ${ }^{(47)}$.

In the majority of studies, patients in the surgical groups have higher Cobb curve magnitudes than the nonsurgical comparison groups $^{(21,22,24,54)}$. Glassman et al. ${ }^{(24)}$ reported that a coronal shift greater than $4 \mathrm{~cm}$ was strongly correlated with a decreased HRQoL and even so they stated that the correction of coronal balance within $4 \mathrm{~cm}$ of neutral may not be as important a goal as restoration of appropriate sagittal alignment. The goal should be a balanced coronal spine, rather than zero straight one. The coronal plane does have an effect on the clinical picture and the postoperative failures but seems to have no statistically significant role in decision making ${ }^{(11,37,51)}$. A clinical note is that patients with a pre-operative trunk shifted to the convex side of the coronal curve are predisposed to having a post-operative coronal imbalance and should be carefully evaluated for decision-making ${ }^{(37,69)}$.

\section{Sagittal Plane Deformity}

In the last decade, spine literature has been reshaped by the "new understanding of sagittal plane analysis". Significant correlations have been detected in ASD between sagittal lumbopelvic parameters and functional outcomes ${ }^{(4,49,51,70)}$. It has been shown in many studies now that positive sagittal balance is the radiographic parameter highly correlated with adverse health status measures, poor clinical outcomes, and also postoperative mechanical complications ${ }^{(13,24,43,57,70)}$. Glassman et al. ${ }^{(23)}$ reported a greater percentage of conservative treatment patients with high symptoms had a diagnosis of sagittal plane deformity $(p<0.01)$ and afterward, compared those 335 highsymptom conservative treatment patients with 476 surgical ASD cases and found a higher incidence of sagittal plane deformity in this time in the surgical group. Schwab et al.(44) also demonstrated that patients with worse scores in back and leg pain presented greater improvements in HRQOL scores postoperatively. Sagittal parameters such as pelvic incidence/ lumbar lordosis (PI-LL) mismatch ${ }^{(21)}$, relative $\mathrm{LL}^{(71)}$ or relative spinopelvic alignment ${ }^{(72)}$ are a strong indicator for pursuing surgical treatment.

\section{Scoring Systems}

\section{Global Alignment and Proportion Score}

The Global Alignment and Proportion (GAP) score is a new PI-based proportional method of analyzing the sagittal plane in patients undergoing surgery for adult spinal deformity. It can either be used for pre and postoperative sagittal analysis and surgical planning(70,71,72). For the study ${ }^{(70)}$, sixth week postoperative sagittal radiograms were evaluated. Adding the age factor as the co-morbidity state, GAP score falls into 3 categories as proportioned ( $0-2$ points), moderately disproportioned (3-6 points), and severely disproportioned (713 points). Each category gives a prediction about mechanical complication occurrence. This revolutionary scoring system has also been validated ${ }^{(2,27,70)}$ and it is still a new concept having ongoing validations.

\section{The Adult Spinal Deformity-Surgical Decision-making Score}

In a very recent article on March 2019 on behalf of European Spine Study Group(21), a total of 316 patients with ASD were analyzed to develop and internally validate a scoring system: the ASD surgical decision-making score, specific to the decisionmaking process for ASD patients younger than 40 years old. A 10-point scoring system was created from four variables: selfimage score in the SRS-22 score, coronal Cobb angle, PI-LL mismatch, and relative spinopelvic alignment, and the surgical indication was graded into low (score 0-4), moderate (score 5-7), and high (score 8-10) surgical indication groups.

Surgical planning is mostly at the preference of the surgeon and also affected by whether the surgeon had a previous history of spinal surgery fellowship training or not ${ }^{(3)}$. Advancing literature supports the benefits of surgical treatment for selected ASD patients, further high-quality studies are required to compare operative and nonoperative treatment. It should be noted that one of the internal difficulties in the designs of these studies is the matter that AS patients referred to a spine surgeon might be more symptomatic and hence not representative of the population as a whole. A majority of AS patients may be treated by their primary care providers and never referred to a tertiary spine center. This may considerably alter the findings in most studies.

\section{CONCLUSION}

A considerable portion of the AS is asymptomatic and maybe never seen by a spine surgeon. Patients with debilitating symptoms, who are referred to the spine surgeons, are mainly decided to pursue surgery mostly influenced by; sagittal plane deformity, functional problems like radicular unbearable leg and lower back pain especially in walking, larger coronal curves, thereby clinical appearance, worse HRQoL measures, surgical indications among the physicians and assessment of medical risk factors. The radiological parameters especially in coronal 
plane, as opposed to AIS, are not as effective as functional limitations and disability in AS for surgery decision-making. Despite high complication rates in adult spinal deformity surgery, benefits patients gain after the surgery overweigh the complication risk. Surgical treatment has the potential to provide significant improvement of leg and back pain in adults with scoliosis. Patients with functional disabilities have a higher tendency to surgical modalities. With the new attempts on classifications and scoring systems, by managing every case according to its own characteristics, surgeon's experience and contentment and the patient's expectations and medical risk stratification will shape the strategy needed to address the pathological processes in adult spinal deformity.

Peer-review: Internally peer-reviewed.

Financial Disclosure: The authors declared that this study received no financial support.

\section{REFERENCES}

1. Aebi M. The adult scoliosis. Eur Spine J 2005; 14:925-48.

2. Bari TJ, Ohrt-Nissen S, Hansen LV, Dahl B, Gehrchen M. Ability of the Global Alignment and Proportion Score to Predict Mechanical Failure Following Adult Spinal Deformity Surgery-Validation in 149 Patients With Two-Year Follow-up. Spine Deform 2019;7:331-7.

3. Bendo JA, Patel A, Yoo A, Lonner B, Protopsaltis T. Fellowship and Practice Composition Affect Surgical Decision Making in Patients with Adult Degenerative Scoliosis: Spinal Deformity versus Degenerative Spinal Surgeons. Int J Spine Surg 2015;9:21.

4. Berven SH, Lowe T. The Scoliosis Research Society Classification for Adult Spinal Deformity. Neurosurg Clin N Am 2007;18:207-13.

5. Bess S, Line B, Fu K-M, McCarthy I, Lafage V, Schwab F, et al. The Health Impact of Symptomatic Adult Spinal Deformity: Comparison of Deformity Types to United States Population Norms and Chronic Diseases. Spine (Phila Pa 1976) 2016;41:224-33.

6. Bess S, Schwab F, Lafage V, Shaffrey Cl, Ames CP. Classifications for adult spinal deformity and use of the Scoliosis Research SocietySchwab Adult Spinal Deformity Classification. Neurosurg Clin N Am 2013;24:185-93.

7. Birknes JK, Harrop JS, White AP, Albert TJ, Shaffrey Cl. Adult degenerative scoliosis: A review. Neurosurgery 2008;63:94-103.

8. Bridwell KH, Glassman S, Horton W, Shaffrey C, Schwab F, Zebala $\mathrm{LP}$, et al. Does treatment (nonoperative and operative) improve the two-year quality of life in patients with adult symptomatic lumbar scoliosis: a prospective multicenter evidence-based medicine study. Spine (Phila Pa 1976) 2009;34:2171-8.

9. Carreon LY, Puno RM, Dimar JR, Glassman SD, Johnson JR. Perioperative complications of posterior lumbar decompression and arthrodesis in older adults. J Bone Joint Surg Am 2003;85:2089-92.

10. Cho KJ, Kim YT, Shin SH, Suk S II. Surgical treatment of adult degenerative scoliosis. Asian Spine J 2014;8:371-81.

11. Cho W, Mason JR, Smith JS, Shimer AL, Wilson AS, Shaffrey $\mathrm{Cl}$, et al. Failure of lumbopelvic fixation after long construct fusions in patients with adult spinal deformity: clinical and radiographic risk factors: clinical article. J Neurosurg Spine 2013;19:445-53.

12. Christiansen PA, LaBagnara M, Sure DR, Shaffrey $\mathrm{Cl}$, Smith JS. Complications of surgical intervention in adult lumbar scoliosis. Curr Rev Musculoskelet Med 2016;9:281-9.

13. D Glassman S, Bridwell K, R Dimar J, Horton W, Berven S, Schwab F. The Impact of Positive Sagittal Balance in Adult Spinal Deformity. Spine (Phila Pa 1976) 2005;30:2024-9.

14. Daubs MD, Lenke LG, Cheh G, Stobbs G, Bridwell KH. Adult spinal deformity surgery: complications and outcomes in patients over age 60. Spine (Phila Pa 1976) 2007;32:2238-44.
15. EUROSPINE 2017 Dublin, Ireland, 11--13 October. Eur Spine J 2017;26:251-91.

16. Everett $C R$, Patel RK. A systematic literature review of nonsurgical treatment in adult scoliosis. Spine (Phila Pa 1976) 2007;32:130-4.

17. Faldini C, Di Martino A, De Fine M, Miscione MT, Calamelli C, Mazzotti $A$, et al. Current classification systems for adult degenerative scoliosis. Musculoskelet Surg 2013;97:1-8.

18. Faraj SSA, Haanstra TM, Martijn H, de Kleuver M, van Royen BJ. Functional outcome of non-surgical and surgical management for de novo degenerative lumbar scoliosis: a mean follow-up of 10 years. Scoliosis spinal Disord 2017;12:35.

19. Ferrero E, Lafage R, Diebo BG, Challier V, Ilharreborde B, Schwab F, et al. Tridimensional Analysis of Rotatory Subluxation and Sagittal Spinopelvic Alignment in the Setting of Adult Spinal Deformity. Spine Deform 2017;5:255-64.

20. Fu K-MG, Smith JS, Sansur CA, Shaffrey Cl. Standardized measures of health status and disability and the decision to pursue operative treatment in elderly patients with degenerative scoliosis. Neurosurgery 2010;6:42-7.

21. Fujishiro T, Boissière L, Cawley DT, Larrieu D, Gille O, Vital JM, et al. Adult spinal deformity surgical decision-making score : Part 1: development and validation of a scoring system to guide the selection of treatment modalities for patients below 40 years with adult spinal deformity. Eur Spine J 2019;28:1652-60.

22. Fujishiro T, Boissière L, Cawley DT, Larrieu D, Gille O, Vital JM, et al. Decision-making factors in the treatment of adult spinal deformity. Eur Spine J. 2018;27:2312-21.

23. Glassman SD, Berven S, Kostuik J, Dimar JR, Horton WC, Bridwell K. Nonsurgical resource utilization in adult spinal deformity. Spine (Phila Pa 1976) 2006;31:941-7.

24. Glassman SD, Schwab FI, Bridwell KH, Ondra SL, Berven S, Lenke LG. The selection of operative versus nonoperative treatment in patients with adult scoliosis. Spine (Phila Pa 1976) 2007;32:93-7.

25. Gremeaux V, Casillas J, Fabbro-Peray P, Pelissier J, Herisson C, Perennou D. Analysis of low back pain in adults with scoliosis. Spine (Phila Pa 1976) 2008;33:402-5.

26. Ha K-Y, Jang W-H, Kim Y-H, Park D-C. Clinical Relevance of the SRSSchwab Classification for Degenerative Lumbar Scoliosis. Spine (Phila Pa 1976) 2016;41:E282-8.

27. Jacobs E, van Royen BJ, van Kuijk SMJ, Merk JMR, Stadhouder A, van Rhijn LW, et al. Prediction of mechanical complications in adult spinal deformity surgery-the GAP score versus the Schwab classification. Spine J 2019;19:781-8.

28. King HA, Moe JH, Bradford DS, Winter RB. The selection of fusion levels in thoracic idiopathic scoliosis. J Bone Joint Surg Am 1983;65:1302-13.

29. Kleimeyer JP, Liu N, Hu SS, Cheng I, Alamin T, Grottkau BE, et al. The Relationship between Lumbar Lateral Listhesis and Radiculopathy in Adult Scoliosis. Spine Spine (Phila Pa 1976) 2019;44:1003-9.

30. Kotwal S, Pumberger M, Hughes A, Girardi F. Degenerative scoliosis: a review. HSS J 2011;7:257-64.

31. Lenke LG, Betz RR, Harms J, Bridwell KH, Clements DH, Lowe TG, et al. Adolescent idiopathic scoliosis: a new classification to determine extent of spinal arthrodesis. J Bone Joint Surg Am 2001;83-A:1169-81.

32. Liu S, Diebo BG, Henry JK, Smith JS, Hostin R, Cunningham ME, et al. The benefit of nonoperative treatment for adult spinal deformity: identifying predictors for reaching a minimal clinically important difference. Spine J 2016;16:210-8.

33. Lonergan T, Place H, Taylor P. Acute Complications After Adult Spinal Deformity Surgery in Patients Aged 70 Years and Older. Clin spine Surg 2016;29:314-7.

34. Lonner BS, Ren Y, Bess S, Kelly M, Kim HJ, Yaszay B, et al. Surgery for the Adolescent Idiopathic Scoliosis Patients After Skeletal Maturity: Early Versus Late Surgery. Spine Deform 2019;7:84-92.

35. Malfair D, Flemming AK, Dvorak MF, Munk PL, Vertinsky AT, Heran MK, et al. Radiographic evaluation of scoliosis: review. AJR Am J Roentgenol. 2010;194:S8-22. 
36. Marty-Poumarat C, Scattin L, Marpeau M, Garreau de Loubresse C, Aegerter P. Natural history of progressive adult scoliosis. Spine (Phila Pa 1976) 2007;32:1227-34.

37. Obeid I, Berjano P, Lamartina C, Chopin D, Boissière L, Bourghli A. Classification of coronal imbalance in adult scoliosis and spine deformity: a treatment-oriented guideline. Eur Spine J 2019;28:94-113.

38. Parent S, Baldus C, Koski T, Brudi P, Giezek H, Tomassini JE, et al. Patient Factors That Influence Decision Making. Spine (Phila Pa 1976) 2015;41:E349-E58.

39. Pekmezci M, Berven SH, Hu SS, Deviren V. The factors that play a role in the decision-making process of adult deformity patients. Spine (Phila Pa 1976) 2009;34:813-7.

40. Pizones ], Pérez Martin-Buitrago M, Perez-Grueso FJS, Vila-Casademunt A, Alanay A, Obeid I, et al. Function and Clinical Symptoms are the Main Factors that Motivate Thoracolumbar Adult Scoliosis Patients to Pursue Surgery. Spine (Phila Pa 1976) 2017;42:E31-E6.

41. Glassman SD, Carreon LY, Shaffrey Cl, Polly DW, Ondra SL, Berven SH, et al. The Costs and Benefits of Nonoperative Management for Adult Scoliosis. Spine (Phila Pa 1976) 2010;35:578-82.

42. Graham RB, Sugrue PA, Koski TR. Adult degenerative scoliosis. Clin Spine Surg 2016;29:95-107.

43. Glassman SD, Berven S, Bridwell K, Horton W, Dimar JR. of radiographic parameters and clinical symptoms in adult scoliosis. Spine (Phila Pa 1976) 2005;30:682-8.

44. Scheer JK, Smith JS, Clark AJ, Lafage V, Kim HJ, Rolston JD, et al. Comprehensive study of back and leg pain improvements after adult spinal deformity surgery: analysis of 421 patients with 2-year follow-up and of the impact of the surgery on treatment satisfaction. J Neurosurg Spine 2015;22:540-53.

45. Schwab F, Dubey A, Gamez L, El Fegoun AB, Hwang K, Pagala M, et al. Adult scoliosis: prevalence, SF-36, and nutritional parameters in an elderly volunteer population. Spine (Phila Pa 1976) 2005;30:1082-5.

46. Schwab F, el-Fegoun AB, Gamez L, Goodman H, Farcy J-P. A lumbar classification of scoliosis in the adult patient: preliminary approach. Spine (Phila Pa 1976) 2005;30:1670-3.

47. Schwab F, Farcy J-P, Bridwell K, Berven S, Glassman S, Harrast J, et al. A clinical impact classification of scoliosis in the adult. Spine (Phila Pa 1976) 2006;31:2109-14.

48. Schwab F, Ungar B, Blondel B, Buchowski J, Coe J, Deinlein D, et al. Scoliosis Research Society-Schwab adult spinal deformity classification: a validation study. Spine (Phila Pa 1976) 2012;37:1077-82.

49. Schwab FJ, Blondel B, Bess S, Hostin R, Shaffrey Cl, Smith JS, et al. Radiographical spinopelvic parameters and disability in the setting of adult spinal deformity: a prospective multicenter analysis. Spine (Phila Pa 1976) 2013;38:E803-12.

50. Sciubba DM, Scheer JK, Yurter A, Smith JS, Lafage V, Klineberg E, et al. Patients with spinal deformity over the age of 75: a retrospective analysis of operative versus non-operative management. Eur Spine J 2016;25:2433-41.

51. Sebaaly A, Grobost P, Mallam L, Roussouly P. Description of the sagittal alignment of the degenerative human spine. Eur Spine J 2018;27:489-96.

52. Shaffrey Cl, Berven S, Hamill C, Glassman S, Hamill C, Horton W, et al. Improvement of Back Pain With Operative and Nonoperative Treatment in Adults With Scoliosis. Neurosurgery 2009;65:86-94.

53. Shaw R, Skovrlj B, Cho SK. Association Between Age and Complications in Adult Scoliosis Surgery. Spine (Phila Pa 1976) 2016;41:508-14.

54. Shelokov A, Burton D, Akbarnia B, Cunningham M, Shaffrey C, Shelokov A, et al. Pain and Disability Determine Treatment Modality for Older Patients With Adult Scoliosis, While Deformity Guides Treatment for Younger Patients. Spine (Phila Pa 1976) 2009;34:2186-90.

55. Simmons ED, Simmons EH. Spinal stenosis with scoliosis. Spine (Phila Pa 1976) 1992;17:S117-20.

56. Slobodyanyuk K, Poorman CE, Smith JS, Protopsaltis TS, Hostin R, Bess $S$, et al. Clinical improvement through nonoperative treatment of adult spinal deformity: who is likely to benefit? Neurosurg Focus 2014;36:E2.
57. Smith JS, Fu K-M, Urban P, Shaffrey Cl. Neurological symptoms and deficits in adults with scoliosis who present to a surgical clinic: incidence and association with the choice of operative versus nonoperative management. J Neurosurg Spine 2011;9:326-31.

58. Smith JS, Lafage V, Shaffrey $\mathrm{Cl}$, Schwab F, Lafage R, Hostin R, et al. Outcomes of Operative and Nonoperative Treatment for Adult Spinal Deformity: A Prospective, Multicenter, Propensity-Matched Cohort Assessment With Minimum 2-Year Follow-up. Neurosurgery 2016;78:851-61.

59. Smith JS, Shaffrey $\mathrm{Cl}$, Berven S, Glassman S, Hamill C, Horton W, et al. Operative versus nonoperative treatment of leg pain in adults with scoliosis: a retrospective review of a prospective multicenter database with two-year follow-up. Spine (Phila Pa 1976) 2009;34:1693-8.

60. Smith JS, Shaffrey Cl, Bess S, Shamji MF, Brodke D, Lenke LG, et al. Recent and emerging advances in spinal deformity. Clin Neurosurg. 2017;80:S77-S85.

61. Smith JS, Shaffrey Cl, Glassman SD, Berven SH, Schwab FJ, Hamill CL, et al. Risk-benefit assessment of surgery for adult scoliosis: An analysis based on patient age. Spine (Phila Pa 1976) 2011;36:817-24.

62. Soroceanu A, Diebo BG, Burton D, Smith JS, Deviren V, Shaffrey C, et al. Radiographical and Implant-Related Complications in Adult Spinal Deformity Surgery: Incidence, Patient Risk Factors, and Impact on Health-Related Quality of Life. Spine (Phila Pa 1976) 2015;40:1414-21.

63. Teles AR, Mattei TA, Righesso O, Falavigna A. Effectiveness of Operative and Nonoperative Care for Adult Spinal Deformity: Systematic Review of the Literature. Glob Spine J 2017;7:170-8.

64. Topp R, Transfeldt E, Mehbod A, Winter R. P141. Surgical Outcomes of Decompression, Decompression with Limited Fusion, and Decompression with Full Curve Fusion for Degenerative Scoliosis with Radiculopathy. Spine J 2008;8:169S.

65. Trammell TR, Schroeder RD, Reed DB. Rotatory olisthesis in idiopathic scoliosis. Spine (Phila Pa 1976) 1988;13:1378-82.

66. Van Goethem J, Van Campenhout A, van den Hauwe L, Parizel PM. Scoliosis. Neuroimaging Clin N Am 2007; 17:105-15.

67. Li G, Passias P, Kozanek M, Fu E, Wang S, Xia Q, et al. Adult Scoliosis in Patients Over Sixty-Five Years of Age. Spine (Phila Pa 1976) 2009;34:2165-70.

68. Yadla S, Maltenfort MG, Ratliff JK, Harrop JS. Adult scoliosis surgery outcomes: a systematic review. Neurosurg Focus 2010;28:E3.

69. Yan P, Liu Z, Zhu F, Bao H, Qiu Y. Coronal imbalance in degenerative lumbar scoliosis. Bone Joint J 2016;98-B:1227-33.

70. Yilgor C, Sogunmez N, Boissiere L, Yavuz Y, Obeid I, Kleinstück F, et al; European Spine Study Group (ESSG). Global Alignment and Proportion (GAP) Score: Development and Validation of a New Method of Analyzing Spinopelvic Alignment to Predict Mechanical Complications After Adult Spinal Deformity Surgery. J Bone Jt Surg 2017;99:1661-72.

71. Yilgor C, Sogunmez N, Yavuz Y, Abul K, Boissiére L, Haddad S, et al. Relative lumbar lordosis and lordosis distribution index: Individualized pelvic incidence-based proportional parameters that quantify lumbar lordosis more precisely than the concept of pelvic incidence minus lumbar lordosis. Neurosurg Focus 2017;43.

72. Yilgor C, Yavuz Y, Sogunmez N, Haddad S, Mannion AF, Abul K, et al. Relative Pelvic Version ( RPV ): An Individualized Pelvic Incidencebased Proportional Parameter that. Spine J 2018;18:1787-97.

73. Zeng Y, White AP, Albert TJ, Chen Z. Surgical strategy in adult lumbar scoliosis: The utility of categorization into 2 groups based on primary symptom, each with 2-year minimum follow-up. Spine (Phila Pa 1976) 2012;37.

74. Zimmerman RM, Mohamed AS, Skolasky RL, Robinson MD, Kebaish KM. Functional outcomes and complications after primary spinal surgery for scoliosis in adults aged forty years or older: a prospective study with minimum two-year follow-up. Spine (Phila Pa 1976) 2010;35:1861-6. 